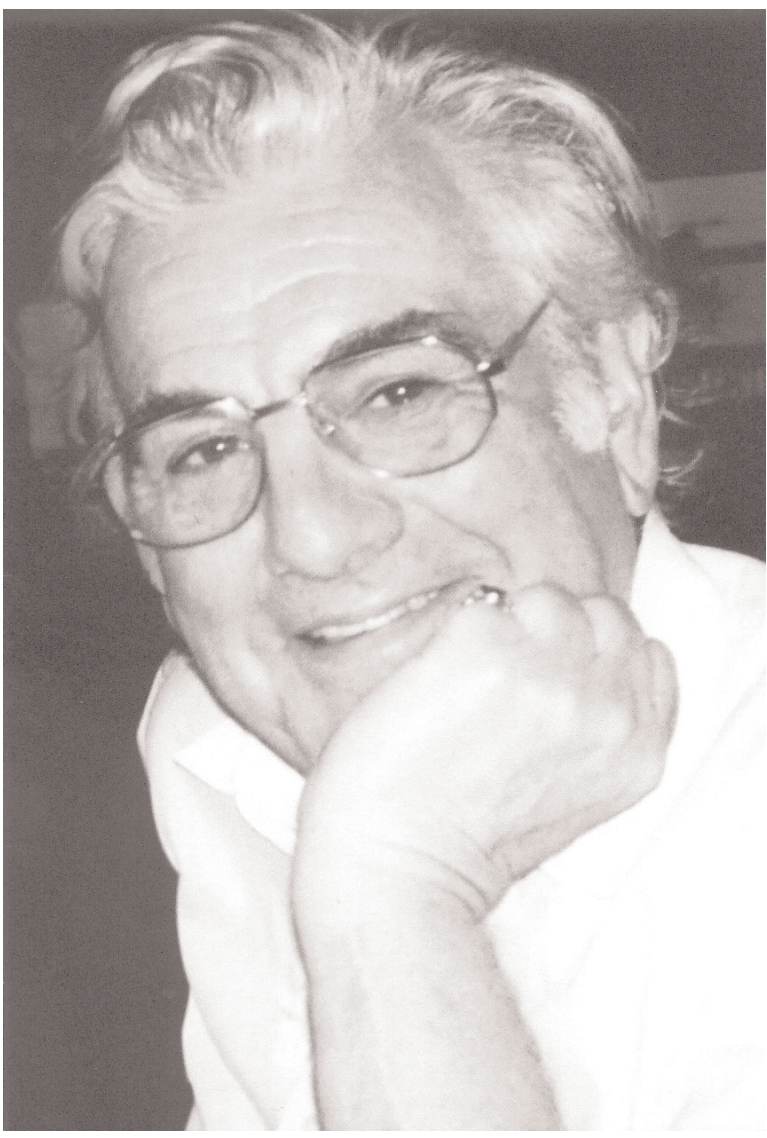

\title{
HANS-CHRISTOPH CURTIUS
}

\author{
31 August 1923 - 13 September 2009
}

Emeritus Professor of Clinical Chemistry, University Children's Hospital, Zürich, Switzerland

It was with great regret that we learnt of the sudden death of Professor Curtius, a founding member of the INTERNATIONAL SOCIETY OF PTERIDINOLOGY. He had a long, brilliant career in scientific research, mainly in biopterin metabolism and has published numerous original papers of great merit. He has been a avid attender of scientific meetings, a brilliant lecturer and as tenacious debater. From the very begin he has been involved in the International Winterworkshops on Clinical, Chemical and Biochemical Aspect of Pteridines held at St.Christoph/Arlberg, Austria in 1982 for the first time, some of which having been organized by him. He was attending this meeting series as long as his health status allowed him to do so. Prof. Curtius will be missed by a large number of friends and colleagues internationally.

\section{Dietmar Fuchs \\ (International Society of Pteridinology)}

On September 13 $3^{\text {th }}, 2009$ Professor Hans-Christoph Curtius died after a long illness at the age of 86. We mourn the loss of an outstanding scientist of world renown, a dear colleague, mentor, and friend, who shaped to a considerable extent international research in the field of inborn errors of metabolism.

With his first pioneering work at the Children's Hospital in Zürich in the field of gas chromatography and mass-spectrometry he introduced new methods as tools for the study of inherited metabolic disorders. In 1972 Curtius and Völlmin demonstrated in vivo that the high concentrations of phenylalanine inhibit dopamine and serotonin formation and they showed that this inhibition is most probably the main reason for the brain damage and neurological symptoms in untreated phenylketonuria (PKU) patients. He also showed by mass-fragmentographic determination of dopamine in human brain biopsies from the caudate nucleus of two untreated PKU patients (plasma phenylalanine $>1800 \mu \mathrm{mol} / \mathrm{L}$ ) that the dopamine content in the brain tissue was extremely low. This was the first ex vivo determination of dopamine in human brain.

In Zürich the most important 25 years of his scientific work began. He published more than 150 papers and was invited to hold numerous lectures that underline his worldwide reputation as scientist. Together with Alois Niederwieser he discovered and characterized a number of inborn errors of tetrahydrobiopterin $\left(\mathrm{BH}_{4}\right)$ metabolism, such as 6-pyruvoyl-tetrahydropterin synthase (PTPS) deficiency and pterin-4a-carbinolamine dehydratase 
(PCD) deficiency. Curtius also played an important role in the characterization of the most important steps in $\mathrm{BH}_{4}$ biosynthesis and from Zürich he conducted the screening for atypical PKU in many countries worldwide. In 1978 Curtius, Schaub and other colleagues treated the first atypical PKU patients with pure $\mathrm{BH}_{4}$.

Hans-Christoph Curtius was honorary professor of clinical chemistry at the Tongaji University in Shanghai and many guest scientists from various parts of the world visited and worked in his laboratory in Zürich. Representative for other colleagues I would just like to mention the following names: Robert Levine, Martin Gal, Haruo Shintaku, Shin-Ichiro Takikawa, Wang Muti, I.Y. Park.

Professor Curtius retired from the University Children's Hospital in Zürich in 1989, but he continued to work in the world of pteridines up to the last moment. The University of Zürich, and the Children's Hospital, pediatricians throughout the world, and his colleagues have lost a dedicated scientist and a dear friend.

\section{Nenad Blau \\ (University Children's Hospital, Zürich, Switzerland)}

